\title{
Frontiers
}

\section{in the Psychotherapy} of Trauma \& Dissociation

Recovered Memories of Child Sexual Abuse: Forgetting to Remember and Remembering to Forget, Part 2: The Nature of Memory and Ordinary Forgetting Sylvia Solinski, Consultant Psychiatrist

The Official Clinical Journal of the International Society for the Study of Trauma and Dissociation 


\title{
Frontiers in the Psychotherapy of Trauma \& Dissociation
}

The Official Clinical Journal of the ISSTD

\section{EDITOR}

ANDREAS LADDIS, MD, Private Practice and Faculty, Boston University, School of Public Health, Boston, Massachusetts, USA

\author{
ASSOCIATE EDITOR \\ MARTIN J DORAHY, PhD, Professor, Department of Psychology, University of Canterbury, \\ Christchurch, New Zealand and The Cannan Institute, Brisbane, Australia
}

\section{EDITORIAL ASSISTANT}

COURTENAY CRUCIL, MA, RCC, Private Practice, Terrace, British Columbia, Canada

\begin{abstract}
Frontiers in the Psychotherapy of Trauma $\mathcal{E}$ Dissociation is published by the International Society for the Study of Trauma and Dissociation, Inc., 4201 Wilson Blvd Third Floor, Arlington, VA 22203
\end{abstract}

\section{Annual Subscription, Volume 4, 2020}

Online subscription is part of the membership dues of the International Society for the Study of Trauma and Dissociation. Visit https://www.isst-d.org/join-isstd/individualmember-benefits/.

Production and Advertising Office: ISSTD Headquarters, 4201 Wilson Blvd Third Floor, Arlington, VA 22203

Copyright $\odot 2020$ International Society for the Study of Trauma and Dissociation. All rights reserved. No part of this publication may be reproduced, stored, transmitted, or disseminated in any for or by any means without prior written permission from the International Society for the Study of Trauma and Dissociation. The publisher assumes no responsibility for any statements of fact or opinion expressed in the published papers. The appearance of advertising in this journal does not constitute an endorsement or approval by the publisher, the editor, the editorial board, or the board of directors of the International Society for the Study of Trauma and Dissociation of the quality or value of the product advertised or of the claims made of it by its manufacturer.

Subscriptions to this journal are acquired through membership in the International Society for the Study of Trauma and Dissociation only.

Visit https://www.isst-d.org/join-isstd/individual-memberhip-categories/.

Permissions. For further information, please write to info@isst-d.org.

\section{EDITORIAL BOARD}

ELIZABETH S BOWMAN, MD, Editor Emerita, Journal of Trauma \& Dissociation, Adjunct Professor of Neurology, Indiana University School of Medicine, Indianapolis, Indiana, USA

LAURA S. BROWN, PhD, Private Practice, Seattle, Washington, USA

RICHARD A CHEFETZ, MD, Private Practice, Faculty and Founding Member Institute of Contemporary Psychotherapy \& Psychoanalysis, Distinguished Visiting Lecturer: William Alanson White Institute of Psychiatry, Psychoanalysis \& Psychology, New York City, USA

CONSTANCE J DALENBERG, PhD, Trauma Research Institute, California School of Professional Psychology, San Diego, California, USA

J.K. JUDITH DANIELS, PhD, Faculty of Behavioural and Social Sciences, University of Groningen, The Netherlands

STEVEN N GOLD, PhD, Professor, Center for Psychological Studies, and Founding Director, Trauma Resolution \& Integration Program, Nova Southeastern University, Fort Lauderdale, Florida, USA ELIZABETH B HEGEMAN, PhD, Professor, Department of Anthropology, John Jay College of Criminal Justice, New York, New York, USA 
RICHARD P. KLUFT, MD, PhD Private Practice and Clinical Professor of Psychiatry, Temple University School of Medicine; Faculty Member, Philadelphia Center for Psychoanalysis,

Philadelphia, Pennsylvania, USA

CHRISTA KRÜGER, MD, Professor of Psychiatry, University of Pretoria, Pretoria, Gauteng, South Africa

KARLEN LYONS-RUTH, PhD, Professor of Psychology, Harvard Medical School, Cambridge, Massachusetts, USA

ALFONSO MARTÍNEZ-TABOAS, PhD, Professor, Albizu University, San Juan, Puerto Rico WARWICK MIDDLETON, MD, Adjunct Professor, Cannan Institute, Brisbane, Australia

ELLERT R. S. NIJENHUIS, PhD, Department of Psychiatry and Outpatient Department Mental Health Care Drenthe, Assen, The Netherlands

SANDRA PAULSEN, PhD, Bainbridge Institute for Integrative Psychology, Bainbridge Island, Washington, USA

VEDAT SAR, MD, Professor of Psychiatry, Koç University School of Medicine (KUSOM), Istanbul, Turkey

JOYANNA SILBERG, PhD, Trauma Disorders Program, Sheppard Pratt Health Systems, Baltimore, Maryland, USA

ELI SOMER, PhD, Professor, School of Social Work, University of Haifa, Israel

KATHY STEELE, MN, CS, Private Practice, Atlanta, Georgia, USA

ONNO VAN DER HART, PhD Emeritus Professor of Psychopathology of Chronic Traumatization, Department of Clinical and Health Psychology, Utrecht University, Utrecht, The Netherlands VICTOR WELZANT, PsyD, Sheppard Pratt Health Systems, Trauma Disorders Program

\section{REVIEWERS}

JOHN BRIERE, PhD, Associate Professor of Psychiatry and Psychology, University of Southern California Keck School of Medicine, Los Angeles, California, USA

SHELDON IZKOWITZ, PhD, Clinical Associate Professor of Psychology and Clinical Consultant, Postdoctoral Program, New York University, New York City, USA and Teaching Faculty \& Supervisor of Psychotherapy and Psychoanalysis, National Institute for Psychotherapies, New York City, USA

MARY-ANNE KATE, PhD Researcher at University of New England, Australia; University of New England, New South Wales, Australia

ULRICH F. LANIUS, PhD, Private Practice, West Vancouver, British Columbia, Canada

\section{SUPPORTERS}

ISSTD thanks its generous supporters whose contributions have made this publication possible:

Andreas Laddis, MD, USA

\section{The \\ Cannan \\ Institute}

Cannan Institute, Australia

Warwick Middleton, MD, Australia

Dana Ross, MD, Canada

Martin J. Dorahy, PhD, New Zealand

Kate McMaugh, Australia

Sara Y. Krakauer, USA

Paula Eagle, MD, USA 


\title{
ARTICLE
}

\section{RECOVERED MEMORIES OF CHILD SEXUAL ABUSE: FORGETTING TO REMEMBER AND REMEMBERING TO FORGET, PART 2: THE NATURE OF MEMORY AND ORDINARY FORGETTING}

\author{
SYLVIA SOLINSKI, Consultant Psychiatrist \\ Malvern Psychotherapy Centre, 1232 Malvern Road, \\ Malvern, VIC 3144, Australia
}

This is the second of three articles on recovered memories of child sexual abuse. The phenomenology of recovered memories is distinct from other, non-traumatic, memories and is most usefully considered in the context of the nature of memory and forgetting. A number of experimental paradigms and approaches that attempt to elucidate the mechanisms of recovered memory are described, and the evidence for the creation of false memories is examined and found wanting. The article concludes with a case study. The third article will consider the role of trauma and dissociation in recovered memories of child sexual abuse.

KEYWORDS phenomenology; memory; forgetting; laboratory studies of errors of omission and commission; false memory

\section{INTRODUCTION}

How abuse is remembered is related to how it is forgotten; "partial forgetting" is consistent with considerable variation in the degree of reported

Acknowledgements: The author is grateful to Martin Dorahy and Andreas Laddis for their help in the preparation of this paper.

Correspondence: Dr. Sylvia Solinski, 5 Mowbray Street, Hawthorn East, VIC 3123, Australia. Email: sylviasolinski@iinet.net.au. 
amnesia (Andrews et al., 2000; Crowley, 2007; Gold et al., 1999; Loftus, Polonsky, \& Fullilove, 1994; Malmo \& Laidlaw, 2010). This includes total forgetting, forgetting some basic knowledge that the abuse happened, forgetting some but not all of the abusive incidents, forgetting some salient facts and episodes, and remembering physical but not sexual abuse. In addition, confusion and doubt regarding memories are common even when childhood abuse has been documented (Williams, 1995). Davies and Frawley (1994) note: "chronic doubts about what did and did not happen, along with a persistent inability to trust one's perceptions of reality, are perhaps the most permanent and ultimately damaging long-term effects of childhood sexual abuse" (p. 109).

Recovered memories may occur within a therapeutic context but, contrary to critics' assertions, are often retrieved in non-treatment settings (Andrews et al., 1995; Elliott, 1997; Feldman-Summers \& Pope, 1994; Malmo \& Laidlaw, 2010). Memories of sexual abuse are involuntarily reactivated by stimuli known as triggers or conditioned stimuli that commonly include current traumatization, the person's children reaching the same developmental stage at which the person was abused, encountering someone who is reminiscent of the perpetrator, experiencing emotional states related to the abuse or physiological states such as hyperarousal, and anniversaries (Van der Hart, Nijenhuis, \& Steele, 2006). Factors associated with past amnesia for abuse include younger age at onset of abuse (Elliott \& Briere, 1995; Widom \& Morris, 1997; Williams, 1995), greater severity of abuse (Elliott \& Briere, 1995; Ghetti et al., 2006; Melchert, 1999), abuse by a perpetrator who is known to and trusted by the child (Epstein \& Bottoms, 2002; Freyd, DePrince, \& Zurbriggen, 2001; Schultz, Lawrence Passmore, \& Yoder, 2002), and family dynamics that foster little (particularly maternal) support and cultivate secrecy (Goodman et al., 2011; Williams, 1995; Ullman, 2007).

\section{The Phenomenology of Recovered Memories}

The majority of recovered memories (but not all) tend to be similar to flashbacks reported by patients with PTSD; they are involuntary, fragmented, accompanied by intense emotion, and experienced as a reliving of the past event (Andrews et al., 2000; Cameron, 1996; Hunter \& Andrews, 2002; Malmo \& Laidlaw, 2010; Roe \& Schwartz, 1996; Van der Hart, Bolt, \& Van der Kolk, 2005; Van der Kolk \& Fisler, 1995). Irrespective of the age at which the trauma occurred, memories are recovered as somatosensory experiences involving visual, kinesthetic, olfactory and auditory modalities which, at least initially, do not occur together. Fear, shock, and disbelief are the most common accompanying emotions and cognitions. Memory emerges gradually in piecemeal fashion over time; Harvey and Herman (1994) clearly documented that people show different phenomenal awareness of the past when recovering memories of trauma and that recovery itself is a complex and variable process. Van der Kolk, Hopper and Osterman (2001) make the 
interesting observation that, unlike the response to questions about traumatic memories, when subjects are asked about somatosensory reliving experiences related to highly significant non-traumatic events (such as a wedding or a graduation ceremony), they find such questions "nonsensi$\mathrm{cal}^{\prime \prime}$ (p. 17).

Assessment of the credibility of recovered memories should be informed by their phenomenology and by the complexity of forgetting and remembering. Yet this is not always the case. For example, the Criteriabased Content Analysis (CBCA), used to analyze the content of an interview, was originally developed for use with children but subsequently its utility has been explored in an adult context (Davies, 2001). The criteria include stipulations that true accounts should be reducible to a coherent and consistent account, should be contextualized in space and time, and should show a clear sequence of development involving actions and reactions. Credibility is deemed greater when there is narrative development and if there are references to the person's feelings or to the presumed feelings of the perpetrator. However, the correlation of credibility with the ability to provide a reflective and nuanced narrative is at odds with the characteristics of recovered memories.

\section{Memory in Context}

\section{Organization}

Since the mid-1960s, models of memory have been influenced by theoretical frameworks derived from information-processing and neuroscience (Schneider \& Bjorklund, 2003). Key aspects of memory models include capacity (reflecting the extent of information and efficient manipulation in short-term and working memories), content (reflecting how memory is represented and remembered), and process (particularly reflecting cognitive processes delineating the traditional memory phases of encoding, storage and retrieval). Consideration of process should include the effects of memory strategies such as attempts to suppress or enhance memory. Furthermore, appraisal and judgement are crucial to assessing the integrity of attributions regarding the source and veridicality of what comes to mind (Burgess \& Shallice, 1996; Putnam, 1997). Understanding recovered memory experiences "principally draws on knowledge and theory about the interplay of memory content and process, including appraisal" (Brewin, 2012, p. 153).

The content of memory may be variously categorized but there is general agreement on the distinction between short-term and long-term memory (Putnam, 2016). Within long-term memory the distinction between implicit (non-declarative) memory and explicit (declarative) memory systems was proposed by Graf and Schacter (1985) and seems to have withstood scientific debate. Implicit memory refers to the influence of experiences that are not consciously accessible but that are manifested by behaviors and emotions. These include habits, skills, some forms of conditioning, 
and the formation of category representations by young infants on the basis of multimodal perceptual experience (Quinn, 2011); generalized representations of repeated experiences form the basis of mental models or schema (Siegel, 2001), including those of early attachment experiences with caregivers. The anticipatory capacity of the brain to retrieve certain memories in response to specific cues (priming), is likewise a function of implicit memory (Schacter \& Buckner, 1998).

Implicit memory involves parts of the brain that do not require conscious processing during encoding or retrieval, is present from birth and remains available throughout development, is not accompanied by a sense that something is being remembered and is enacted or embodied rather than expressed verbally (Schneider, 2011); during the normal period of "childhood amnesia", events that are experienced across multiple modalities but that cannot be linguistically represented will continue to influence later emotional, perceptual and behavioral experiences. Implicit memory is characterized as slow (with the exception of priming, it results from gradual or incremental learning), reliable and inflexible (tied to a specific modality or context).

In contrast, explicit memory is characterized as fast (e.g., supporting one-trial learning), fallible (e.g., memory traces degrade; retrieval failures occur), and flexible (Bauer, Larkina, \& Deocampo, 2011). It is mediated by medial-temporal and diencephalic brain structures that do not mature until the second year of life, and by the prefrontal cortex which matures later. Explicit memory requires conscious, focal attention during encoding in order to activate the hippocampus which organizes spatiotemporal sequencing (Siegel, 1999) and, more generally, binds sensorimotor inputs from multiple brain regions to create a durable integrated memory trace (Bauer et al., 2011). Explicit memory involves a sense of "remembering", may be verbally expressed, includes semantic memory (for facts and concepts) and episodic memory (for events and experiences). It also includes the accompanying source memory (for the how or where of what is known) which strongly influences confidence in the accuracy of the memory (Putnam, 2016).

\section{Autobiographical Memory}

Memory and identity are inextricably linked (Brewer, 1986). The selfdefining aspect of memories for past facts, events and experiences is particularly critical to autobiographical memory which encompasses memories about one's self. It has been postulated that identity involves multiple "selves" that are experienced at different times and in different contexts (Harter, Bresnick, Bouchey, \& Whitesell, 1997; Markus \& Sentis, 1982); as goal-oriented "working selves" are activated, identity is experienced in overlapping ways. These correspond to a set of related structures in long-term memory that 
contain both some constant features of the self and information relating to the self in specific roles (Conway \& Pleydell-Pearce, 2000). Relatedly, albeit from the very different perspective of relational psychoanalysis, Bromberg (1998) has written at length about "the loose configuration of multiple selfstates that enables a person to feel like one self while being many" (p. 12).

There is a widespread view that autobiographical memory is hierarchically organized (Conway, 2005; Hudson \& Mayhew, 2009). Overarching, conceptual, long-term knowledge about the self is immediate, requires no retrieval search and is salient to identity (e.g., knowing that one has parents and siblings and where the family lived). This higher-level semantic knowledge should be distinguished from schematic individual episodic memories for experiences that are detailed and contextualized and which can be voluntarily retrieved but may also be retrieved automatically by internal or external cues (e.g., knowing that a holiday was spent at a school camp). Whether and to what extent retrieval occurs is conditioned by and influences episodic memories in the service of the person' goals. At the third level there is event-specific or sensation-based information relating to individual events that, unlike contextualized episodic memories are not subject to voluntary retrieval but, rather, are automatically retrieved in response to (often very specific) internal or external cues (e.g., the smell of pine associated with a visit to a forest) (Conway, 2009). This summary record of sensory-perceptual processing can influence cognition indirectly "by priming, directly by combining with more abstract personal knowledge in the formation of a memory and, ultimately, by being recollectively experienced" (Conway \& Pleydell-Pearce, 2000, p. 272).

\section{Goal-Oriented Action}

A teleological view of human behavior has long been postulated (Adler, 1929; Allport, 1954; James, 1890/1950; Järvilehto, 1998) whereby observable behavior or action is taken is order to achieve desired goals that subserve higher-order motivational propensities. During the past 20 years, evidence has accumulated that, similarly to many areas of cognitive processing (e.g., attention and perception, Schneider \& Shiffrin, 1977; Shiffrin \& Schneider, 1977), motives and goal activation occur at both conscious and nonconscious levels of awareness (Woike, 2008). A goal may be defined as a cognitive representation of a future object that a person is committed to approach or avoid. It is a regulatory construct "adopted and represented in memory until the goal is achieved or the reason for adopting the goal is abandoned, altered or successfully addressed through another route" (Elliot \& Niesta, 2009, p. 66-67). This mental representation presumably includes information regarding the goal.

However, like schemas, goals may not be consciously selected but, rather, may be triggered or primed by one's environment and interactions with significant others (Bargh \& Huang, 2009). Moreover, even when a goal 
is consciously selected at a certain time, it may subsequently be accessed and pursued implicitly; "people can behave, interact, and pursue their goals without knowing precisely why they are doing so, or what process has put various objectives in their mind" (Kruglanski \& Kopetz, 2009, p. 352). Furthermore, goal-relevant responding requires that the person value the goal in order for the priming to be more than mere activation of the concept of the goal. In short, goals are governed by the same principles as other cognitive or knowledge structures such as categories, judgements, or concepts in which the automaticity inherent in implicit processes, facilitates flexibility and self-regulation within the ambit of an individual's otherwise limited (conscious) resources.

Explicit (conscious) motives relate to people's self-attributed, articulated goals and values that are activated by extrinsic or social incentives such as rewards, prompts, expectations or demands and focus on specific, often unmet, goals (Elliot \& Niesta, 2009). The link to conscious goal setting, includes the formulation of plans and rules for behavior "that corresponds with values and the self-concept and, therefore, should involve highly elaborated networks of knowledge about the self and one's values" (Woike, 2008, p. 104).

Implicit (nonconscious) motives relate to people's enduring preferences for certain types of emotional experiences are linked to intrinsic incentives (i.e., enjoying something for its own sake) and predict behavioral trends over time rather than immediate responses to specific situations (Koestner, Weinberger, \& McClelland, 1991; Winter, John, Stewart, Klohnen, \& Duncan, 1998). Implicit motives may be linked to automatic informationprocessing events that result in desired affective end states (e.g., being loved; feeling virtuous); non-verbal stimuli and perceptual images are more likely to be encoded with rich imagery (Schultheiss \& Hale, 2006) and rehearsed in order to reexperience the pleasure associated with the implicit motive (Woike, 1994).

Research that relates motivational influences and goals to memory is nascent (Bender, Woike, Burke, \& Dow, 2012; Moskowitz \& Grant, 2009; Murayama \& Elliot, 2011). This is quite a void given the importance of motivational processes for autobiographical memory (Bender \& Woike, 2010), and hence for a vital aspect of a person's identity (Bluck, 2003Although there is a consensus that goals are represented in memory (Bargh, 1990; Kruglanski, 1996; Moskowitz, Li, \& Kirk, 2004), fluctuate in accessibility and can activate many memories that interconnect in certain (excitatory, inhibitory) ways, the nature of these representations remains unclear.

Current models of autobiographical memory link situational, activated explicit motives to self-concept, current goals and plans and, therefore, facilitate episodic memory that fosters goal achievement and/or maintenance of a sense of self-consistency (Conway \& Pleydell-Pearce, 2000). When autobiographical memory for social information is elicited by implicit motives, 
individuals tend to organize social information about other people in ways that relate to those motives via strategies that facilitate the attainment of a desired affective end state (Woike, 2008): "Identifying the relation between implicit and explicit motives and the aspects of events that relate to these motives provide a great deal of explanatory power for the question of why some experiences are remembered and others are forgotten" (Woike, 2008, p. 114).

The degree of concordance between motivational systems and the environmental factors that elicit them, may be salient to understanding the relationship between affect and cognition in modulating the accessibility of autobiographical memories. Congruence between one's implicit motives and explicit goals is positively linked to well-being (Brunstein, Schultheiss, \& Grässman, 1998); implicit motives may energize effort and involvement, whereas explicit motives guide choice and planned action (Brunstein \& Maier, 2005). On the other hand, someone with a strong implicit but weak explicit motive who is preoccupied with past emotional experiences would experience little correlation between the preoccupation and goal achievement; there is little or no awareness of the motive-specific emotional experience which may hinder progress toward current self-attributed goals (Woike, 2008).

\section{Memorabilia}

The ability to retrieve information about one's personal history is predicated on efficient encoding and consolidation which reflect interactive processes between developing prefrontal cortical and medial temporal structures (Bauer, 2006). Various accounts of the onset and development of autobiographical memory include cognitive (Howe \& Courage, 1997), cognitive-motivational (Conway \& Pleydell-Peace, 2000) and social interactionist (Fivush, 2009). Irrespective of which account is privileged, the increasing capacity to coherently organize information that is critical to memory advances in childhood is, to a great extent, contingent on early interpersonal experiences (Schore, 2009; Siegel, 2001). For example, a maternal reminiscing style that is more elaborative both during and after an event is crucial to a child's ability to narrate their personal past experiences (Bauer et al., 2011; Fivush, 1998); participating in detailed and adult-guided conversation helps children report their past experiences in a narrative that is more detailed and coherent. Relatedly, since meta-awareness facilitates incorporation of experience into the individual's autobiographical life, narrative experiences that are encoded with explicit reflection as to their meaning may be more accessible to volitional retrieval (Shobe \& Schooler, 2001). Furthermore, the coherence of the parent's autobiographical narrative is a robust predictor of their child's attachment style; a coherent narrative is correlated with secure attachment which is requisite to the development of an autobiographical sense of self (Siegel, 2001; Van IJzendoorn, 1995). 


\section{REMEMBERING IN CONTEXT}

\section{General Characteristics}

From age three years on, children's reports of familiar and recurrent events such as going to McDonald's are generalized and temporally structured (Nelson \& Gruendel, 1981). Reports of what usually occurs are in the timeless present tense and, almost always, in the correct temporal order. This conforms to a "script" model in which actions during recurring events are specified by spatially and temporally organized frameworks (Schank \& Abelson, 1977) indicating an ability to extract commonalities across experiences. (e.g., "You get a happy meal, you eat it, you go down the slide and my mummy takes me home."). Novel or one-off events such as holidays or trips to amusement parks are able to be described in accurate detail by children aged three years and may be remarkably well remembered for 18 months to 5 years (Fivush, 1998).

However, both children and adults have difficulty reporting a specific instance of a repeated event (Hudson, Fivush, \& Kuebli, 1992); the report is general, focusing on what usually happens and details of specific experiences are omitted or confused among episodes. Memory is associative (responsive to cues) and shows significant state-dependent learning effects such that the information learned in one state may be relatively inaccessible while the individual is in a different state (Dalenberg, 2006; Lindsay \& Read, 2001). There is a bias to spontaneously remember events associated with mild positive affect (Conway \& Pleydell-Pearce, 2000) and when people conclude that a distinctive event did not occur, they may do so on the basis that their inability to remember indicates event non-occurrence (Ghetti, 2003). Remembering is affected by normal processes of decay across time (Read \& Lindsay, 2000), and of interference whereby recall of one set of information "interferes" with the ability to recall the other (Sivers, Schooler, \& Freyd, 2002). Remembering is generally enhanced by less conscious avoidance, more repetition or rehearsal, by the greater salience of events (Dalenberg, 2006) and by better integration of events with the person's identity (Conway, 2005).

\section{Effect of Emotion}

Levels of emotional arousal can both enhance and impair memory (Brewin, 2011); within the range of everyday events emotionally arousing events are better remembered than mundane events, whereas for extraordinary events there is evidence that extreme emotion leads to both unforgettable experiences (as evidenced by the flashbacks of PTSD) and to experiences that are forgotten (Van der Kolk, 2014). Studies have found that levels of stress or anxiety: a) correlate with poorer performance on eyewitness memory for various types of information (Deffenbacher, Bornstein, Penrod, \& 
McGorty, 2004); b) affect memory for peripheral details while preserving memory for central details (Waring, Payne, Schacter, \& Kensinger, 2010); and c) impair children's memory for stressful medical procedures when these are not discussed with caregivers (Fivush, 1998). The first central pass of sensory input is to the thalamus where partial evaluation occurs before transmission for further evaluation to both the amygdala and the prefrontal cortex. The amygdala is crucially involved in attributions of significance or emotional valence prior to conscious emotional experience, and influences brainstem areas that control behavioral, autonomic and neuro-hormonal responses (LeDoux, 1996). The intensity of input from the amygdala to the hippocampus determines the extent of organization and the likelihood that an event will be remembered. The evidence that extreme stress damages the hippocampus is impressive and, for the past 25 years an inverted U-shaped function relating stress levels to learning and memory (Yerkes \& Dodson, 1908) has been a frequent research finding (Dalenberg, 2006; Nijenhuis, 2015; Sivers et al., 2002). It seems that events encoded under prevailing conditions of both too little and too much stress may not be memorable.

\section{Reconstruction and Retrieval}

Remembering is a complex phenomenon that manifests omissions, uncertainty and distortions in various ways (Lindsay \& Read, 2001). Common experience and research findings converge in demonstrating that an individual who cannot remember an event in some circumstances may remember it in other circumstances. Cueing may prompt recall or recognition may be immediate. Some aspects of an event may be remembered but not others, for example remembering that a particular event happened but not when and where. An individual may know that an event happened without remembering anything about it. Research on implicit memory demonstrates that, in the absence of remembering, performance on indirect tests of memory may be influenced by past events (Shobe \& Schooler, 2001). It is generally agreed that memory is either partially or wholly reconstructive; the act of remembering involves the active linking of encoded event-related information with mental models, perceptual biases, associated memories, information and emotions (Putnam, 1997). That is, autobiographical remembering draws on knowledge structures while incorporating other current aspects of the self, such as goals, motivation and mood state (Conway \& PleydellPearce, 2000).

A useful consideration in the investigation of remembering is the "remember-know" distinction (Mandler, 1980; Tulving, 1985) that has influenced research into episodic memory retrieval. Individuals may know or believe (based on evidence and/or a sense of familiarity) that an autobiographical event occurred without having any accompanying recollective experience such as imagery. For individuals to know something is for them to be aware "that the information was successfully retrieved from memory 
despite the absence of personal involvement or any accompanying contextual detail" (Mickes, Seale-Carlisle, \& Wixted, 2013, p. 334). Essentially, it entails a feeling of familiarity irrespective of whether it is the result of an act of recall (e.g., knowing that Paris is the capital of France) or an act of recognition (e.g., encountering a person who is somehow known without knowing how he/she is known). Knowing accesses information that involves semantic memory which provides the symbolically representable information an individual has assimilated about themselves and the world (Vandekerckhove \& Panksepp, 2011). Such a factual understanding of things is a manifestation of memory that is predicated on noetic consciousness which entails both being aware of what one is thinking and of being aware of such awareness (Tulving, 2002). For example, a man may know that World War II lasted from 1939 to 1945 and that his father served in the army for two of those years before he was injured and sent home.

In contrast, for individuals to remember an event is to appreciate that it is a part of their personal past (Mickes et al., 2013). Such an appreciation is an ability to experience the past episodically and necessarily involves the conscious retrieval or recollection of the individual perceptual, affective and/or cognitive contextual details that serve to cue the individual as to when and how the information was learned. An individual is able "to remember the encoding of specific information, associated with specific feelings, on particular occasions within specific contexts... guided apparently by factors, of great self-relevance, because they are intimately related to each individual's unique feelings, thoughts, goals and behaviors" (Vandekerckhove \& Panksepp, 2009, p. 1024-1025). For example, a person may remember that she had gone to the bank on a particular day in order to withdraw money in anticipation of her child's first music lessons which she could now afford because she had received a job promotion and a pay rise. On the same day she had felt a sense of vindication and celebrated by having a drink with friends despite thinking that this was unwise as she still had work to complete.

Episodic remembering is a manifestation of memory that is predicated on autonoetic consciousness which refers to explicit self-awareness "and/or the explicit awareness of something or someone else in a specific time-space context" (Vandekerckhove \& Panksepp, 2011, p. 2023). This highest form of consciousness reflects the capacity to mentally represent enduring existence, to possess and act with a sense of temporal continuity that encompasses both past and future selves. The information the person is aware of includes information about the source from which prior information was learned as well as the temporal reference of an event; individuals are able to select an event as a reference point and to judge whether a recollected event came before or after this point of reference (Vandekerckhove \& Panksepp, 2011). 
The evaluation and appraisal of the veracity of one's own recollective experiences is complex as evidenced by studies on source memory (Johnson, 2006). Brewer (1986) has suggested three criteria according to which it may be gauged whether an individual has remembered a past event: a belief that the event was personally experienced ("autobiographical belief"); the accompanying presence of imagery; and a requisite degree of confidence that the imagery is a veridical record of the event ("memory confidence"). Distinguishing between these different types of judgement is important in evaluating the literature on the creation of false memories.

\section{Memory in the Laboratory}

\section{Errors of Omission}

It is often thought that forgetting is undesirable and that when people forget a variety of childhood events such as music lessons and attending summer camps, this may simply reflect the passage of time and passive factors such as decay of memory traces, changes in environmental context and the accumulation of similar, interfering, experiences in memory (Read, 1997; Read \& Lindsay, 2000). However, the motivation to forget is ubiquitous as people fend off memories of unpleasant or embarrassing experiences. Does isolating or limiting awareness of memories result in amnesia? Freyd (1996) argues that, if a child who is abused by a trusted caregiver is to maintain the necessary attachment to that caregiver, then there is intense motivation to keep the abuse out of mind. There is extensive research on cognitive avoidance and its negative effects on memory and a range of experimental paradigms have examined the possible mechanisms of motivated forgetting. Some of these are now explored.

i) Directed forgetting. There are two experimental variants that examine whether people can intentionally forget recently encountered information. In the item-method (Golding, 2005) stimuli such as words or pictures are presented one at a time to subjects who are told that, following each item, they will receive instructions directing them to either remember or forget it. Typically, substantially more remember items than forget items are recalled or recognized. This may result from truncated encoding whereby subjects intentionally stop elaborative encoding until they are given further instructions, and continue to elaborate only those items that are to be remembered (Basden, Basden, \& Gargano, 1993).

In contrast, in the list-method a whole list is presented before subjects receive the remember or forget instruction, at which point a second list is presented; memory for the first list is impaired in subjects who were instructed to forget it compared with subjects who were told to remember both lists. As the instruction is unexpected, subjects are likely to maintain efforts to encode until it is given. 
The effect has been attributed to both a retrieval deficit (Basden et al., 1993) and to intentional shifts in mental context between the first and second lists (Sahakyan \& Kelley, 2002). Accordingly, the forgetting effects typically disappear when recognition memory is tested (showing that forgotten items remain intact in memory) though not when recognition memory places greater demands on context memory (Sahakyan, Waldum, Benjamin, \& Bickett, 2009). For example, impaired recognition is found with lists of nonwords (but not with lists of words). It is hypothesized that nonwords, which (unlike words) lack a prior history of occurrence in multiple contexts, form stronger item-to-context associations during encoding. Furthermore, in the absence of semantic meaning, context may be interactively encoded with nonwords resulting in a temporary meaning whose robustness is subject to a close match between conditions during encoding and those during testing.

ii) Suppressing retrieval of unwanted memories. Anderson and Huddleston (2012) report the results of a combined analysis of 47 experiments conducted with 2174 participants; cue-target pairs are used as probes in a paradigm that mimics situations in which people stumble upon a reminder of a memory that they prefer not to think about and try to keep out of mind. It was found that "when people are motivated to avoid being reminded of an unwanted memory, reminders do not merely fail to enhance memory; they actually trigger processes that impair retention of the suppressed memory" (Anderson \& Huddleston, 2012, p. 63). Two mechanisms for forgetting unwanted memories were investigated. First, thought substitution, in which the retrieval of alternative diversionary thoughts is learned, is consistent with the selective retrieval hypothesis (Anderson \& Green, 2001) whereby victims of abuse are forced to retrain their response to reminders of unwanted memories by selectively retrieving alternative thoughts and memories about the abuser. Second, direct retrieval suppression, in which participants are instructed not to allow distraction by thought substitution but, rather, to focus on the cue and actively block out the unwanted associate if it happens to come to mind.

Although both mechanisms generate memory impairment (Bergström, de Fockert, \& Richardson-Klavehn, 2009), only direct suppression effects generalized to independent probe test cues; cue-independent forgetting suggests that instructions to directly expel a memory from awareness are implemented by an inhibitory process that suppresses the unwanted trace. Moreover, the effect is enhanced with advance warning, generally builds with repetition (Levy \& Anderson, 2008), generalizes to non-verbal material (visual objects and faces) and emotional memories (Depue, Banich, \& Curran, 2006; Depue, Curran, \& Banich, 2007) and is "greater in people with more traumatic experiences" (Anderson \& Huddleston, 2012, p. 82) as assessed by the Brief-Betrayal Trauma Survey (Goldberg \& Freyd, 2006). 
Neuroimaging research (Depue et al., 2007) reveals that inhibitory mechanisms are associated with increased activation in the prefrontal cortex and decreased activation in the hippocampal regions; inhibition is also associated with decreased activation in (especially right) amygdala activity in response to emotional stimuli. Electrophysiological research (Bergström et al., 2009; Mecklinger, Parra, \& Waldhauser, 2009) reveals that direct suppression reduces the conscious recollection of an event having been previously experienced and that electrophysiological markers of cognitive control are larger during retrieval suppression.

Anderson and Huddleston (2012) make several other noteworthy observations. For example, the findings to date indicate that retrieval suppression may last between one day and one week; longer trial duration has been correlated with less suppression indicating that inescapable cues provide particularly strong challenges to cognitive control requiring sustained efforts over time to achieve full control over unwanted memories (Lee, Lee, \& Tsai, 2007). Developmentally, there is a progression in cognitive control as reflected in retrieval-induced forgetting; strikingly, 8-9 year olds show no suppression and 11-12 year olds show an intermediate ability to suppress compared with adults. This occurs in the context of overall improvements in declarative memory during middle childhood and is consistent with increasingly effective coupling of the fronto-parietal-hippocampal network that is involved in the process of remembering and forgetting. Cases of "psychogenic amnesia" whereby memories of violent events "are forgotten abruptly via an unconscious defence mechanism" (Anderson \& Huddleston, 2012, p. 109) are not well addressed by retrieval suppression which begins as an intentional act and improves gradually with practice.

These are serious shortcomings for a theory that needs to accommodate the fact that children are required to withstand abuse that may often be perpetrated from an age far younger than middle childhood. Irrespective, according to a flexible control hypothesis, it is suggested that motivated forgetting may involve flexibly targeted response control mechanisms. Itemmethod directed forgetting may model encoding suppression; list-method directed forgetting may reflect temporal context suppression; and retrieval suppression captures situations in which encoding has already succeeded, a later reminder triggers an unwanted memory and response override is likely to be more important. However, Anderson and Levy (2009) note that there is little research on the effect on implicit memory in the context of suppression of unwanted memories. Moreover, under some conditions there is increased accessibility of unwanted memories following thought suppression (Wenzlaff \& Wegner, 2000).

iii) Forgetting prior remembering. Individuals can believe that they had forgotten abuse at a time at which they are known to have been aware of it. They may, for example, have talked about it to someone but forgotten 
that they had done so. This phenomenon of underestimating prior knowledge of an experience has been termed the "forgot-it-all-along" (FIA) effect (Schooler, 2001) and may be understood within a theoretical framework of meta-awareness. People's experiential consciousness (i.e., the contents of phenomenological experience) can be distinct from meta-awareness (i.e., the consciousness of consciousness) and an individual's "discovered" memories of abuse involve abrupt changes in their meta-awareness of the abuse. Changes include:

a) Reinterpreting the abuse as abuse resulting from discovering the meaning of the abuse and its implications for the individual's selfunderstanding.

b) Regaining access to the meta-awareness that had accompanied the abuse but had diminished in the aftermath of the abuse. For example, a person may move to a new location where the opportunities for encountering cues that are relevant to the abuse are fewer. Additionally, when recollections and reflections about the abuse are consistently avoided, it becomes less memorable and fails to reinforce the meta-awareness regarding the abuse. Hence, memory of the abuse (which includes the meta-awareness) is not truly forgotten or entirely unavailable, and when there is a recollection that is unable to be ignored, the accompanying meta-awareness is likewise accessed. Interestingly Anderson and Huddleston (2012) propose that meta-memory amnesia may be explained by retrieval suppression which targets both reminders of the abuse and thoughts that the individual has about it during the period of remembering.

c) Acquiring a novel meta-awareness that had not been encoded at the time of the abuse as a result of a lack of discussion and explicit reflection; young age precluding the likelihood of self-reflection; stress which reduces the activation of the prefrontal cortex thereby interfering with both selfawareness and the integration of memories into readily retrievable autobiographical memories; dissociation in which detachment to the point of depersonalization precludes meta-awareness; and nocturnal occurrence of abuse that precedes or follows sleep and is interspersed with dreaming.

The FIA effect has been found in a number of studies (Abenavoli \& Henkel, 2009; Arnold \& Lindsay, 2002; Raymaekers, Maarten, Smeets, Abidi, \& Merckelbach, 2011) and memory-for-memory accuracy improves when stimuli are thought about in the same context in which they were initially presented, and when additional time is spent on emotional and perceptual cueing. In an unusual study, in which women were asked to describe both their experiences of abuse and their experiences of remembering and forgetting the abuse, Fivush and Edwards (2004, p. 14) found that their results "complement" Schooler's findings. In a study that similarly explored the narrative themes of CSA survivors, those who reported recovered memories also reported feeling highly distressed and overwhelmed, and experiencing periods of loss of functioning. High levels of denial of sexual abuse were 
also reported in this group (MacIntosh, Fletcher, \& Collin-Vézina, 2016). Sivers et al. (2002) note that "in the context of an emotional onrush associated with thinking about memories of abuse, individuals may assume that they had no previous knowledge about their abuse" (p. 180).

Schooler (2001) surmises that experiential memories of abuse (particularly when they are disjunctive with other schema) may elude retrospective meta-awareness until specific abuse-related cues are encountered. The shock and disbelief when this occurs may be accompanied by misattributions whereby the experience of discovering a meta-awareness of a prior event is confused with the discovery of the memory itself. It follows that, in the absence of meta-awareness, memories of CSA may be susceptible to distortions and source monitoring errors.

\section{No Errors: The Trauma Myth}

In contrast to those who claim that CSA is forgotten because it was traumatic, there is a counterclaim that it is forgotten because it is not traumatic (McNally, 2007, 2012; McNally \& Geraerts, 2009). Within a framework of PTSD in which trauma is predicated on violence or threat of violence "CSA need not qualify as a canonical traumatic stressor that provokes terror and fear for one's life" (McNally, 2012, p. 140). In typical CSA, a child aged about 7 years, who is fondled on one to several occasions by a known and trusted perpetrator who neither threatened nor physically harmed the victim, experiences "confusion, disgust, or anxiety" (McNally, 2012, p. 140). Although the victim is able to avoid thinking about the experience "precisely because it was not traumatic in the sense of being terrifying" (McNally, 2012, p. 140), reminders in adulthood result in a re-conceptualization of the experience as sexually exploitative and may result in PTSD.

McNally maintains that CSA is morally reprehensible: "we can accept the fact that children are often resilient and still categorically condemn sexual contact between children and adults" (McNally, 2012, p. 140). McNally's sanguine view of CSA is at odds with the literature on the malevolent dynamics between victims and perpetrators, the enabling of abuse of bystanders (Middleton, 2017; Solinski, 2017) and on the devastating and far-ranging sequelae of childhood adversity. For example, in the Adverse Childhood Experiences (ACE) Study, Felitti et al. (1998) found that the clear majority of patients who were exposed to one category of childhood abuse or household dysfunction were also exposed to at least one other, and that there was a graded relationship between the breadth of exposure to adversity during childhood and multiple risk factors for several of the leading causes of death in adults.

Using data from the ACE study, Edwards, Freyd, Dube, Anda and Felitti (2012) found that high betrayal trauma as a result of CSA was linked to greater depression, anxiety, anger and suicidality, and to a greater risk of sexual revictimization. The literature on the devastating sequelae of CSA 
across all developmental domains is vast (Silberg, 2013) and the evidence for its etiological role in the "trauma spectrum disorders" (Bremner, 2002) compelling. McNally (2007) ponders the issue of survival: "If one fails to survive, one dies. But it is unclear how the child would perish. Would the perpetrator murder the child? Would he expose the child to fatal neglect, such as refusing to feed her? Would he evict her from the parental home?" (p. 290). The emphasis on literal death implies that attachment behaviors in children would only emerge when survival is imminently threatened but, as Freyd, DePrince and Gleaves (2007) note, an extensive attachment literature demonstrates the contrary. Threats to survival come in many guises and the effort to maintain their attachment relationship in an attempt to elicit caregiving and to avoid violence and/or neglect, requires that children isolate knowledge of abuse.

\section{Errors of Commission: Memory Distortions}

i) Source monitoring framework (SMF). The SMF posits that information which specifies the source of a memory is, typically, not directly retrieved together with the memory. Rather, the ability to identify and attribute the source of remembered information depends on evaluations made on the basis of the phenomenal characteristics of the activated information and on the types of decision processes applied (Johnson \& Raye, 1981; Johnson \& Raye, 2000).

Johnson, Raye, Mitchell, and Ankudowich (2012) postulate that "remembering" is an attribution about a current mental experience that is based on characteristics of the mental experience that include information such as percepts (e.g. color), context (e.g. spatio-temporal features), semantic concepts, emotion, cognitive activities (e.g., retrieving additional information; evaluating plausibility), familiarity and recency. Such information guides judgements about the origin of a mental experience and, generally, people correctly infer that an event is real, imagined or dreamed. However, the distribution of characteristics may overlap resulting in misattributions (e.g., a vivid dream is mistaken for a real event).

Memory attributions are influenced by prior knowledge, belief and socio-cultural practices. Deliberately created images and thoughts are less likely to be misattributed to a perceptual (external) source consistent with the fact that cognitive operations are encoded and can later be cues to source (Johnson, Kahan, \& Raye, 1984). "Importing" or "borrowing" similar features is a potent source of memory distortion that may generate high confidence in memories constructed from aspects of actual events (Lyle \& Johnson, 2006), and accurate memories are enhanced by importing features from similar memories (Lyle \& Johnson, 2007). The effect of emotion on source memory is complex and depends on its role. For example, it may foster a greater sense of recollection or confidence independent of accuracy 
(Talarico \& Rubin, 2003), enhance within-object binding of features and impair associations between an object and its context (Mather, 2007).

Motivation can affect all aspects of source memory influencing, for example, "the kinds of events or features of events that are attended to initially, are thought or talked about after an event, and are accessed or given the most weight later during remembering. ... people may selectively attend to or remember positive rather than negative information to regulate mood ... or misattribute information to sources based on desired outcome" (Johnson et al., 2012, p. 23). Doubt is extremely functional in that "it may be the cue for further efforts at remembering, seeking corroboration, reserving judgment, or deciding to live with ambiguity" (Johnson et al., 2012, p. 20).

To reiterate, source monitoring depends on the nature of the memory under evaluation and on the types of decision processes applied in making that evaluation. The experience of an inability to specify source information can range from mildly disconcerting (e.g., repeating a story to the same person on different occasions) to profoundly disruptive (e.g., an illness characterized by delusions). A severe disruption in remembering source may be a salient feature of all forms of amnesia (Mayes, Meudell, \& Pickering, 1985).

\section{The DRM Paradigm}

The literature on memory errors in laboratory tasks has important implications for misremembering. Many laboratory studies using various paradigms have yielded evidence consistent with the SMF (Mitchell \& Johnson, 2000). One of the most widely used tasks to study memory errors has been the Deese-Roediger-McDermott (DRM) paradigm (Roediger \& McDermott, 1995), which measures the tendency to falsely recall that an associated item was presented in a list of thematically related words. The DRM paradigm has been used to assess vulnerability for false memories of CSA. Such vulnerability has been found in people who score high on a measure of dissociation (Winograd, Peluso, \& Glover, 1998), people in whom there is autobiographical distortion for a public event (Platt, Lacey, Iobst, \& Finkelman, 1998), people with PTSD who report histories of CSA both in adults (Bremner, Schobe, \& Kihlstrom, 2000) and in adolescents (Goodman et al., 2011), and in women who report recovered memories of sexual abuse (Clancy, Schacter, McNally, \& Pitman, 2000)

DePrince et al. (2012) make astute observations regarding the interpretation and generalization of the research on misremembering details. First, there is a difference between misremembering details for an event that actually occurred (i.e., the DRM task) and falsely recalling an entirely new event that never occurred (i.e., CSA). Second, some subgroups may perform no differently with respect to correctly recalling the studied words; a reasonable assumption is that individuals may be correct regarding the gist of an event (i.e. that CSA occurred) whereas misremembering the details 
of that event. Third, individuals who are prone to misremembering details of actual events may misremember an abusive childhood as more positive than it was, a strategy that is consistent with the ability to maintain attachment to abusive caregivers. This is in keeping with the SMF which, as noted, highlights the importance of similarity in source memory errors: "the most compelling false memories seem to come from importation of features from real memories of actually perceived events rather than from imagination alone" (Johnson, 2006, p. 762).

ii) Creating false memories for childhood autobiographical events. Three paradigms have been employed in experimental attempts to investigate whether possible within therapy memory distortions for childhood events can be created (Brewin \& Andrews, 2017). The amount of apparent corroboration (e.g., participants are told that events which did not happen were witnessed by others ) and explicit suggestion (e.g., participants' experience of a known false event is "confirmed" by a family member and a doctored photograph of the event is provided) increases in the studies as follows: imagination inflation studies that require participants to imagine false events; false feedback studies in which mainly generic false information is given to suggest the likelihood of having experienced an event; memory implantation studies in which false corroboration from family members or from doctored photographs is offered to suggest the occurrence of a false event.

a) Imagination inflation studies. Participants imagine events initially rated as unlikely that occurred to them before the age of 10 years (e.g., getting stuck in a tree). Self-report measures of confidence in autobiographical belief indicate small increases in a minority of participants that some have characterized as reducing the belief that the event did not happen rather than increasing the belief that it did happen (Smeets, Merckelbach, Horselenberg, \& Jelicic, 2005). This is a far cry from the episodic memory that is associated with autonoetic consciousness, whereby an individual's experience of a past event involves an appreciation that it is a part of their personal past.

b) False feedback studies. Typically, participants re-rate their confidence in their belief that events (e.g., liking or not liking certain foods) happened to them before the age of 10 years after receiving false feedback that the event was likely to have happened. A minority of participants' autobiographical beliefs can be manipulated showing somewhat stronger average effects than the imagination inflation studies. This appears to be a robust effect that is found across diverse suggested events. Most studies have also relied on self-report to assess recollective experience but the results have been highly inconsistent reflecting, inter alia, the difficulty of ascertaining whether an experience is "best described as a memory or a belief" (Brewin \& Andrews, 2017, p. 13). However, as with the imagination studies, increases in confidence levels rarely exceeded the scale midpoint and the results might be construed as indicating a reduction in disbelief rather 
than an actual belief that the event occurred. Clearly, whether an individual recollects an event or believes that it happened without recollecting it, is fundamental to the interpretation of the false feedback studies; at the very least it is premature to generalize to episodic memory and to note that, such recollective events as are produced may, in keeping with the source memory framework, partly correspond to actual events rather than to events that never happened.

c) Memory implantation studies. Typically, after consultation with a family member, a particular event is targeted as a false event prior to age 10 years (e.g., being lost in a shopping mall; a ride in a hot air balloon) that participants are encouraged to recall. In some cases, false corroboration is enhanced by other material and sometimes guided imagery is used. Ratings are investigator-based and attempts are made to distinguish "partial" memories (e.g., those that were vague, incomplete or not necessarily believed to be real) from "full" or "complete" memories (Loftus \& Pickrell, 1995). Some studies included self-report measures of autobiographical belief that false events had actually happened.

The results are highly variable and a high proportion of "memories" of false events are speculative, partial or only in the form of images, engender doubts regarding their authenticity and are not rated as comparable with memories of true events (Brewin \& Andrews, 2017). Although use of guided imagery resulted in higher rates of investigator-based false memory judgements, "self-reports of belief in and memory of false suggested events are similarly low for studies with and without guided imagery instructions" (Brewin \& Andrews, 2017, p. 18) This is consistent with the SMF (Johnson, 2006) which predicts that, while the products of imagination may be confused with real memories, in the absence of careful and explicit questions they may also be attributed to the cognitive operations employed. Hence, judgements of false memory may be inflated.

\section{DISCUSSION}

The data are inconsistent with claims that false memories of childhood events are easily created (Conway, 2013). Despite the very high levels of demand (Hyman \& Pentland, 1996) and the use of guided imagery, doctored photos, and the involvement of trusted others, most participants are resistant to suggestion. In keeping with the SMF which emphasizes the complexity of evaluating truth and falsity in autobiographical memory, there is caution and uncertainty about recollective experiences, appropriate discrimination in participants' ratings of confidence in true and false memories, and production of more detail for true events (Qin, Ogle, \& Goodman, 2008). However, the fact that some people are convinced that created false memories have occurred is important to explain and attempts have been made to do so. 
Hyman and Pentland (1996) note that in all their studies "the suggestions regarding an event do not appear to be adopted wholesale. Rather what appears to occur is that the individual considers the suggestions in light of other self-knowledge (e.g., self-schema, personal memories), and constructs a memory that is a combination of the suggestion plus related self-knowledge" (p. 112). The suggestion that even full false memories are at least partially constructed from veridical autobiographical elements is consistent with a model proposed by Pezdek, Finger and Hodge (1997). According to this model a necessary condition for creating false memories is that the suggested event must be plausible as when, for example, it is suggested that its occurrence is prevalent in others (not just in the general population) with whom the person has much in common (Pezdek \& Blandon-Gitlin, 2009). To the extent that it is consonant with their personal experiences, providing detailed information about the target event also influences peoples' beliefs (Pezdek, Blandon-Gitlin, Lam, Hart, \& Schooler, 2006).

DePrince et al. (2012) suggest that: "gaining knowledge about sexual abuse may be more likely to produce false memories of sexual abuse if one possesses relevant experiences to which that knowledge might apply. For example, gaining knowledge about sexual abuse might be more likely to influence the memories of individuals who recall dysfunctional relationships to which additional sexual details could be added, and be less likely to influence memories of individuals without dysfunctional childhood relationships" (p. 211).

An interesting twist to the false memory critique has come from some of its staunchest adherents (Patihis, Frenda, \& Loftus, 2018) whose study looked at the correlation between a number of paradigms including imagination inflation, post-event misinformation and the DRM task. They found that evidence of memory distortion in one paradigm was not predictive of false memories in other paradigms. Moreover, no relationship was found between laboratory-elicited false memory and significant news events that were used to index autobiographical memory distortion. The authors concluded that "false-memory proneness may only meaningfully vary with respect to individuals with memory impairments, whereas all other individuals can develop false memories given the right circumstances" (Patihis et al., 2018, p. 156). However, the lack of evidence of ecological validity is harnessed in the service of casting doubt on memories of abuse.

\section{CASE STUDY}

C (a composite of several patients) was a 28 single woman who, together with a sister 5 years her senior, had been brought up on a farm in rural Australia by her father and stepmother. Her parents had divorced when she was aged two years and a brother 12 years her senior lived with their 
mother. Her father, though not unkind, was busy and brusque, and unable to protect her from her stepmother's criticism, physical abuse and neglect which included inadequate food and clothing. $C$ recalled that he would sometimes bathe her and that there were occasional offerings of sweets from her father at times when he took her with him while doing farm work. Sometimes he would hoist her into a tree with her beloved pet dog where she would sit for long periods and stare out as her father tended to his animals.

$\mathrm{C}$ and her sister attended a small school where she was bullied despite her sister's attempts to involve teachers and to help by physically intervening. Her father gruffly told her to ignore it. Her best times, about which she continually daydreamed, were when her brother visited for 7-10 days every two months. He was physically affectionate and generally nice to her; he took her tractor riding, swimming, and climbed trees with her on the farm. He also stood up for her so that she had more to eat during his visits. She loved him and was devastated each time he left. C did well enough academically to gain entry to university and at age 18 years she moved to the city where she shared a student house with her sister and a young man who looked like her brother.

He was gentle and kind and the friendship between himself and $C$ developed into a relationship when she turned 20 years. Thereafter there was an onset of bouts of depression, frequent feelings of dread that was ostensibly non-specific, panic attacks in the context of sexual arousal and episodes of regression during which she would climb into her boyfriend's lap and suck her thumb while insisting that he hug and rock her. $C$ started to see a therapist to whom she reported a longstanding recurrent dream in which, while naked, she was tightly held by a man wearing gumboots. On one occasion, during one of their baths together, C screamed at her boyfriend, froze and experienced a flashback of her father fondling her in the bath.

Encouraged by her therapist whose active therapeutic focus was on her flashback, $C$ reported her father to the police. During the ensuing investigation, when C's sister was interviewed she stated that the sisters had always shared a bath when living on the farm and were left to wash themselves. On the one occasion that their father had tried to help, his wife had screamed at him to "take off his dirty gumboots" and to get out of the bathroom. Furthermore, she had often been out with $C$ and their brother, and had witnessed him removing $C^{\prime}$ s clothes and fondling her, both when they were in the pool and in a tree. The sister also stated that $C$ had often told her that their brother was the only person who loved her and that she had felt safest when sitting in his lap while he stroked her.

C's boyfriend corroborated that he had likewise been told this by $C$ on a number of occasions. $\mathrm{C}$ did not remember saying this previously to either 
her sister or to her boyfriend. When the police interviewed C's brother, he admitted that he had abused her from when she was aged three to ten years. Recently, moreover, he had been suspended from his job as a primary school teacher pending investigation of allegations of "inappropriately touching" children of both sexes in his care. C was devastated to "learn" that she had been sexually abused by her brother and, following an attempt to cut her wrists in the bath, she was referred to me and I organized a hospital admission. During a stormy inpatient stay, she evinced a mix of emotions including anger regarding her brother's betrayal of her, revulsion at her "complicity" and an implacable conviction that she was worthless and a waste of everyone's time. She refused to see her father who was a frequent visitor.

Following discharge, she severed contact with her family and broke off her relationship. Post discharge, therapy was short-lived and characterized by C's insistence that she had been betrayed by her father, sister and boyfriend who had maligned the brother by whom she had always been loved and cherished. She reported frequent nightmares of being entangled in a tree that was being chopped down by a man who was oblivious to her cries. When I asked her who the man was, she said that she couldn't see because he was obscured by the foliage. Following her brother's conviction and incarceration, $\mathrm{C}$ ceased therapy when she moved to the town where the prison was located, and visited her brother regularly with baskets of food. She withdrew from university where she had been studying to become a vet, found a job as a waitress and fostered dogs that had been injured in accidents or abused by their owners.

Three years after ceasing therapy, $\mathrm{C}$ contacted me in order to resume therapy. Whether this was a "resumption" or a beginning was something to which we would subsequently return. At our first session $C$ told me that, following a nightmare in which she had "sensed" that the man chopping down the tree was her brother, she had taken an overdose. She barely survived treatment in the intensive care unit of a hospital in which she refused to speak to the psychiatrist other than to say that she wanted her to call me.

\section{CASE DISCUSSION}

The sequence of C's memory trajectory exemplifies the activation of imagination inflation (e.g., the therapist's detailed enquiries seeking elaboration of C's father's behavior while she was in the bath and her encouragement of $C$ to report these details to the police ), source monitoring errors (e.g., $C^{\prime}$ 's attribution of abuse in the pool by her brother to being abused in the bath by her father), a failure of meta-awareness (e.g., C telling her sister and boyfriend that her brother had fondled her in the tree which she understood as an affectionate, rather than abusive, act; forgetting that she had told 
her sister and boyfriend), and the recurrent isolation of information that had been "known" all along (e.g., C's recurrent dream; C severing relations with her family, ceasing therapy and relocating in order to remain in close proximity to her brother). Were there things that I could have or should have done differently? Perhaps so, but the outstanding dynamic in her presentation was her intense attachment to her brother in the service of which she gave up her close relationships, her study and therapy. In challenging this I would have risked the significant likelihood that $C$ would decompensate and possibly suicide. C's identity was predicated on remembering that, amidst the deprivation, physical and emotional abuse of her youth, she had been loved by a brother who cherished her and singled her out for special and devoted attention.

Put differently, her goal of being loveable and being loved by her brother was paramount and incompatible with other possible goals such as reconciling with her father, pursuing a career and exploring a current, loving relationship. Various cognitive mechanisms enabled C to "forget" the sexual abuse by her brother ensuring that he remained the loving center of her otherwise emotionally dysregulated and barren life. Yet, the memory remained, albeit distorted and hidden from her. The symptoms manifested by $\mathrm{C}$ represented the implicit inkling of the illusory nature of her goal; when the implicit was made explicit in her dream, her goal was shattered as was her life. Her decision to return to therapy was, in effect, a decision to contemplate the possibility of exploring an alternative self and an alternative life. She knew that she wanted to be a vet and C undertook therapy in the authentic albeit painful pursuit of other, as yet to be determined, goals. Much later she told me that my voice asking, "who was the man", had been "like a glass shard" that she had repeatedly and unsuccessfully tried to remove.

\section{CONCLUSION}

Memories of sexual abuse may be kept at bay, especially when a trusted caregiver is the perpetrator. Their apparent sudden emergence is often preceded by recurrent intimations and relating of the abuses that are promptly "forgotten". Memories are often fragmented and, irrespective of the survivor's conviction regarding their veracity, may be "remembered" in ways that do not correspond to what actually happened. It is vital that therapists refrain from probing for detail and from encouraging patients to take action. Premature challenges to a patient's defenses may precipitate regression, consolidate re-enactment, obscure the nature of adaptive goals, and delay therapeutic progress. These issues are revisited in the third and final article which examines the relationship between dissociation and memory. 


\section{REFERENCES}

Abenavoli, R., \& Henkel, L. A. (2009). Remembering when we last remembered our childhood experiences: Effects of age and context on retrospective metamemory judgments. Applied Cognitive Psychology, 23(5), 717-732. https:/ / doi.org/10.1002/acp.1502

Adler, A. (1929). The practice and theory of individual psychology. London, UK: Kegan Paul.

Allport, G. W. (1954). The nature of prejudice. Reading, MA: Addison-Wesley.

Anderson, M. C., \& Green, C. (2001). Suppressing unwanted memories by executive control. Nature, 410(6826), 366-369. https:/ / doi.org/10.1038/35066572

Anderson, M. C., \& Huddleston, E. (2012). Towards a cognitive and neurobiological model of motivated forgetting. In R. F. Belli (Ed.), True and false recovered memories: Toward a reconciliation of the debate (pp. 53-120). New York, NY: Springer.

Anderson, M. C., \& Levy, B. T. (2009). Suppressing unwanted memories. Current Directions in Psychological Science, 18(4), 189-194. https://doi.org/10.1111/ j.1467-8721.2009.01634.x

Andrews, B., Brewin, C.R., Ochera, J., Morton, J., Bekerian, D. A., Davies, G. M., \& Mollon, P. (2000). The timing, triggers and qualities of recovered memories in therapy. British Journal of Clinical Psychology, 39(1), 11-26. https:/ / doi.org/10.1348/014466500163077

Andrews, B., Morton, J., Bekerian, D. A., Brewin, C. R., Davies, G. M., \& Mollon, P. (1995). The recovery of memories in clinical practice: experiences and beliefs of British psychological society practitioners. The Psychologist: Bulletin of the British Psychological Society, 8(5), 209-214.

Arnold, M. M., \& Lindsay, D. S. (2002). Remembering remembering. Journal of Experimental Psychology: Learning, Memory, and Cognition, 28(3), 521-529. https:/ / doi.org/10.1037/0278-7393.28.3.521

Bargh, J. A. (1990). Auto-motives: Preconscious determinants of social interaction. In E. T. Higgins \& R. M. Sorrentino (Eds.), Handbook of motivation and cognition: Foundations of social behavior, Vol 2 (pp. 93-130). New York, NY: Guilford Press.

Bargh, J. A., \& Huang, J. Y. (2009). The selfish goal. In G. B. Moskowitz \& H. Grant (Eds.), The psychology of goals (pp. 127-150). New York, NY: Guilford Press.

Basden, B. H., Basden, D. R., \& Gargano, J. G. (1993). Directed forgetting in implicit and explicit memory tests: A comparison of methods. Journal of Experimental Psychology: Learning, Memory, and Cognition, 19(3), 603-616. https://doi.org/ 10.1037 / / 0278-7393.19.3.603

Bauer, P. J. (2006). Constructing a past in infancy: A neuro-developmental account. Trends in Cognitive Sciences, 10(4), 175-181. https://doi.org/10.1016/j.tics. 2006.02.009

Bauer, P.J., Larkina, M., \& Deocampo, J. (2011). Early memory development. In U. Goswami (Ed.), The Wiley-Blackwell handbook of childhood cognitive development (pp.153-179). Chichester, UK: Wiley-Blackwell.

Bender, M., \& Woike, B.A. (2010). Learning and memory correlates of implicit motives. In O. C. Schultheiss \& J. C. Brunstein (Eds.), Implicit motives (pp. 211-244). New York, NY: Oxford University Press. 
Bender, M., Woike, B. A., Burke, C. T., \& Dow, E. A. A. (2012). The relationship between implicit and explicit motives, goal pursuit, and autobiographical memory content during a diary study. Journal of Research in Personality, 46(4), 374-383. https://doi.org/10.1016/j.jrp.2012.03.005

Bergström, Z. M., de Fockert, J. W., \& Richardson-Klavehn, A. (2009). ERP and behavioural evidence for direct suppression of unwanted memories. NeuroImage, 48(4), 726-737. https: / / doi.org/10.1016/j.neuroimage.2009.06.051

Bluck, S. (2003). Autobiographical memory: Exploring its functions in everyday life. Memory, 11(2), 113-123. https:/ / doi.org/10.1080/741938206

Bremner, J. D. (2002). Does stress damage the brain?: Understanding trauma-based disorders from a mind-body perspective. New York, NY: W. W. Norton \& Company.

Bremner, J. D., Shobe, K. K., \& Kihlstrom, J. F. (2000). False memories in women with self-reported childhood sexual abuse: An empirical study. Psychological Science, 11(4), 333-337. https:/ / doi.org/10.1111/1467-9280.00266

Brewer, W. F. (1986). What is autobiographical memory? In D. C. Rubin (Ed.), Autobiographical memory (pp. 25-49). Cambridge, UK: Cambridge University Press.

Brewin, C. R. (2011). The Nature and significance of memory disturbance in posttraumatic stress disorder. Annual Review of Clinical Psychology, 7(1), 203-227. https:/ / doi.org/10.1146/annurev-clinpsy-032210-104544

Brewin, C. R. (2012). A theoretical framework for understanding recovered memory experiences. In R. F. Belli (Ed.), True and false recovered memories: Toward a reconciliation of the debate (pp. 149-173). New York, NY: Springer.

Brewin, C. R., \& Andrews, B. (2017). Creating memories for false autobiographical events in childhood: A systematic review. Applied Cognitive Psychology, 31(1), 2-23. https://doi.org/10.1002/acp.3220

Bromberg, P. M. (1998). Standing in the spaces: Essays on clinical process, trauma, and dissociation. Hillsdale, NJ: Analytic Press.

Brunstein, J. C., \& Maier, G. W. (2005). Implicit and self-attributed motives to achieve: Two separate but interacting needs. Journal of Personality and Social Psychology, 89(2), 205-222. https:/ / doi.org/10.1037/0022-3514.89.2.205

Brunstein, J. C., Schultheiss, O. C., \& Grässman, R. (1998). Personal goals and emotional well-being: The moderating role of motive dispositions. Journal of Personality and Social Psychology, 75(2), 494-508. https://doi.org/10.1037//00223514.75.2.494

Burgess, A. W., Hartman, C. R., \& Baker, T. (1995). Memory presentations of childhood sexual abuse. Journal of Psychosocial Nursing $\mathcal{E}$ Mental Health Services, 33(9) 9-16. https:/ / doi.org/10.3928/0279-3695-19950901-04

Burgess, P. W., \& Shallice, T. (1996). Confabulation and the Control of Recollection. Memory, 4(4), 359-411. https:/ / doi.org/10.1080/096582196388906

Cameron, A. (1996). Comparing amnesic and nonamnesic survivors of childhood sexual abuse: A longitudinal study. In K. Pezdek \& W. P. Banks (Eds.), The recovered memory/false memory debate (pp. 41-68). San Diego, CA: Academic Press.

Clancy, S. A., Schacter, D. L., McNally, R. J., \& Pitman, R. K. (2000). False recognition in women reporting recovered memories of sexual abuse. Psychological Science, 11(1), 26-31. https:/ / doi.org/10.1111/1467-9280.00210 
Conway, M. A. \& Pleydell-Pearce, C. W. (2000). The construction of autobiographical memories in the self-memory system. Psychological Review, 107(2), 261-288. https: / / doi.org/10.1037/ /0033-295x.107.2.261

Conway, M. A. (2005). Memory and the self. Journal of Memory and Language, 53(4), 594-628. https://doi.org/10.1016/j.jml.2005.08.005

Conway, M. A. (2009). Episodic memories. Neuropsychologia, 47(11), 2305-2313. https://doi.org/10.1016/j.neuropsychologia.2009.02.003

Conway, M. A. (2013). On being a memory expert witness: Three cases. Memory, 21(5), 566-575. https: / / doi.org/10.1080/09658211.2013.794241

Crowley, M. S. (2007). Memories of childhood sexual abuse: Narrative analyses of types, experiences, and processes of remembering. Journal of Interpersonal Violence, 22(9), 1095-1113. https: / / doi.org/10.1177/0886260507302879

Dalenberg, C. (2006). Recovered memory and the Daubert criteria: Recovered memory as professionally tested, peer reviewed, and accepted in the relevant scientific community. Trauma, violence, and Abuse, 7(4), 274-310. https:/ / doi.org/ $10.1177 / 1524838006294572$

Davies, G. M. (2001). Is it possible to discriminate true from false memories? In G. M. Davies \& T. Dalgleish (Eds.), Recovered memories: Seeking the middle ground (pp. 153-174). Chichester, UK: Wiley.

Davies, J. M., \& Frawley, M. G. (1994). Treating the adult survivor of childhood sexual abuse: A psychoanalytic perspective. New York, NY: Basic Books.

Deffenbacher, K. A., Bornstein, B. H., Penrod, S. D., \& McGorty, E. K. (2004). A metaanalytic review of the effects of high stress on eyewitness memory. Law and Human Behaviour, 28(6), 687-706. https://doi.org/10.1007/s10979-004-0565-x

DePrince, A. P., Brown, L. S., Cheit, R. E., Freyd, J. J., Gold, S. N., Pezdek, K., \& Quina, K. (2012). Motivated forgetting and misremembering: Perspectives from betrayal trauma theory. In R. F. Belli (Ed.), True and false recovered memories: Toward a reconciliation of the debate (pp. 193-242). New York, NY: Springer.

Depue, B. E., Banich, M. T., \& Curran, T. (2006). Suppression of emotional and nonemotional content in memory: effects of repetition on cognitive control. Psychological Science, 17(5), 441-447. https://doi.org/10.1111/j.14679280.2006.01725.x

Depue, B. E., Curran, T., \& Banich, M. T. (2007). Prefrontal regions orchestrate suppression of emotional memories via a two-phase process. Science, 317(5835), 215-219. https://doi.org/10.1126/science.1139560

Edwards, V. J., Freyd, J. J., Dube, S. R., Anda, R. F., \& Felitti, V. J. (2012). Health outcomes by closeness of sexual abuse perpetrator: A test of betrayal trauma theory. Journal of Aggression, Maltreatment \& Trauma, 21(2), 133-148. https:/ / doi.org/10.1080/10926771.2012.648100

Elliot, A. J., \& Niesta, D. (2009). Goals in the context of the hierarchical model of approach-avoidance motivation. In G. B. Moskowitz \& H. Grant (Eds.), The psychology of goals (pp. 56-76). New York, NY: Guilford Press.

Elliott, D. M. (1997). Traumatic events: Prevalence and delayed recall in the general population. Journal of Consulting and Clinical Psychology, 65(5), 811-820. https: / / doi.org/10.1037/0022-006x.65.5.811

Elliott, D. M., \& Briere, J. (1995). Posttraumatic stress associated with delayed recall of sexual abuse: A general population study. Journal of Traumatic Stress, 8(4), 629-647. https://doi.org/10.1002/jts.2490080407 
Epstein, M. A., \& Bottoms, B. L. (2002). Explaining the forgetting and recovery of abuse and trauma memories: Possible mechanisms. Child Maltreatment, 7(3), 210-225. https://doi.org/10.1177/1077559502007003004

Feldman-Summers, S. \& Pope, K. S. (1994). The experience of "forgetting" childhood abuse: A national survey of psychologists. Journal of Consulting and Clinical Psychology, 62(3), 636-639. https://doi.org/10.1037//0022-006x.62.3.636

Felitti, V. J., Anda, R. F., Nordenberg, D., Williamson, D. F., Spitz, A. M., Edwards, V., Koss, M. P., \& Marks, J. S. (1998). Relationship of childhood abuse and household dysfunction to many of the leading causes of death in adults: the adverse childhood experiences (ACE) study. American Journal of Preventive Medicine, 14(4), 245-258. https:/ / doi.org/10.1016/s0749-3797(98)00017-8

Fivush, R. (1998). Children's recollections of traumatic and nontraumatic events. Development and Psychopathology, 10(4), 699-716. https://doi.org/10.1017/ s0954579498001825

Fivush, R. (2009). Sociocultural perspectives on autobiographical memory. In M. L. Courage \& N. Cowan (Eds.), The development of memory in infancy and childhood (pp.283-301). Hove, UK: Psychology Press.

Fivush, R., \& Edwards, V. J. (2004). Remembering and forgetting childhood sexual abuse. Journal of Child Sexual Abuse, 13(2), 1-19. https://doi.org/10.1300/ j070v13n02_01

Freyd, J. J. (1996). Betrayal trauma: The logic of forgetting childhood abuse. Cambridge, MA: Harvard University Press.

Freyd, J. J., DePrince, A. P. \& Gleaves, D. H. (2007). The state of betrayal trauma theory: Reply to McNally - conceptual issues, and future directions. Memory, 15(3), 295-311. https:/ / doi.org/10.1080/09658210701256514

Freyd, J. J., DePrince, A. P. \& Zurbriggen, E. L. (2001). Self-reported memory for abuse depends upon victim-perpetrator relationship. Journal of Trauma $\mathcal{E}$ Dissociation, 2(3), 5-15. https: / /doi.org/10.1300/j229v02n03_02

Ghetti, S. (2003). Memory for nonoccurrences: The role of metacognition. Journal of Memory and Language, 48(4), 722-739. https:/ /doi.org/10.1016/s0749596x(03)00005-6

Ghetti, S., Edelstein, R. S., Goodman, G. S., Cordòn, I. M., Quas, J. A., Alexander, K. W., Redlich, A. D., \& Jones, D. P. H. (2006). What can subjective forgetting tell us about memory for childhood trauma? Memory $\mathcal{E}$ Cognition, 34(5), 1011-1025. https:/ / doi.org/10.3758/bf03193248

Gold, S. N., Hughes, D. M., \& Swingle, J. M. (1999). Degrees of memory of childhood sexual abuse among women survivors in therapy. Journal of Family Violence, 14(1), 35-46. https:/ / doi.org/10.1023/A:1022813925852

Goldberg, L. R., \& Freyd, J. J. (2006). Self-reports of potentially traumatic experiences in an adult community sample: Gender differences and test-retest stabilities of the items in a brief betrayal-trauma survey. Journal of Trauma $\mathcal{E}$ Dissociation, 7(3), 39-63. https:/ /doi.org/10.1300/j229v07n03_04

Golding, J. M. (2005). Directed forgetting tasks in cognitive research. In A. Wenzel \& D. C. Rubin (Eds.), Cognitive methods and their application to clinical research (pp. 177-196). Washington DC: American Psychological Association. 
Goodman, G. S., Ogle, C. M., Block, S. D., Harris, L. S., Larson, R. P., Angusti, E, ...Urquiza, A. (2011). False memory for trauma-related Deese-RoedigerMcDermott lists in adolescents and adults with histories of child sexual abuse. Development and Psychopathology, 23(2), 423-438. https://doi.org/10. $1017 /$ s0954579411000150

Graf, P., \& Schacter, D. L. (1985). Implicit and explicit memory for new associations in normal and amnesic subjects. Journal of Experimental Psychology: Learning, Memory, and Cognition, 11(3), 501-518. https://doi.org/10.1037/02787393.11.3.501

Harter, S., Bresnick, S., Bouchey, H. A., \& Whitesell, N. R. (1997). The development of multiple role-related selves during adolescence. Development and Psychopathology, 9(4), 835-853. https:/ /doi.org/10.1017/s0954579497001466

Harvey, M. R., \& Herman, J. L. (1994). Amnesia, partial amnesia and delayed recall among adult survivors of childhood trauma. Consciousness and Cognition, 3(3-4), 295-306. https:/ / doi.org/10.1006/ccog.1994.1017

Howe, M. L., \& Courage, M. L. (1997). The emergence and early development of autobiographical memory. Psychological Review, 104(3), 499-523. https://doi. org/10.1037/0033-295x.104.3.499

Howell, E.F. (2011). Understanding and treating dissociative identity disorder: A relational approach. New York, NY: Routledge.

Hudson, J. A., Fivush, R., \& Kuebli, J. (1992). Scripts and episodes: The development of event memory. Applied Cognitive Psychology, 6(6), 483-505. https://doi.org/10.1002/acp.2350060604

Hudson, J.A., \& Mayhew, E. M. Y. (2009). The development of memory for recurring events. In M. L. Courage \& N. Cowan (Eds.), The development of memory in infancy and childhood (pp. 69-91). Hove, UK: Psychology Press.

Hunter, E. C. M., \& Andrews, B. (2002). Memory for autobiographical facts and events: a comparison of women reporting childhood sexual abuse and nonabused controls. Applied Cognitive Psychology, 16(5), 575-588. https:/ / doi.org/ 10.1002/acp.815

Hyman, I. E. \& Pentland, J. (1996). The role of mental imagery in the creation of false childhood memories. Journal of Memory and Language, 35(2), 101-117. https:/ / doi.org/10.1006/jmla.1996.0006

James, W. (1890/1950). The principles of psychology, (Vols. 1 \& 2). Mineola, NY: Dover Publications.

Järvilehto, T. (1998). The theory of the organism-environment system: I. Description of the theory. Integrative Physiological and Behavioral Science, 33(4), 321-334. https://doi.org/10.1007/bf02688700

Johnson, M. K. (2006). Memory and reality. American Psychologist, 61(8), 760-771. https:/ / doi.org/10.1037/0003-066X.61.8.760

Johnson, M. K., \& Raye, C. L. (1981). Reality monitoring. Psychological Review, 88(1), 67-85. https:/ / doi.org/10.1037//0033-295x.88.1.67

Johnson, M. K., \& Raye, C. L. (2000). Cognitive and brain mechanisms of false memories and beliefs. In D. L. Schacter \& E. Scarry (Eds.), Memory, brain, and belief (pp. 35-86). Cambridge, MA: Harvard University Press.

Johnson, M. K., Kahan, T. L., \& Raye, C. L. (1984). Dreams and reality monitoring. Journal of Experimental Psychology: General, 113(3), 329-344. http:/ /dx.doi.org/ 10.1037/0096-3445.113.3.329 
Johnson, M. K., Raye, C. L., Mitchell, K. J., \& Ankudowich, E. (2012). The cognitive neuroscience of true and false memories. In R. F. Belli (Ed.), True and false recovered memories: Toward a reconciliation of the debate (pp. 15-52). New York, NY: Springer.

Koestner, R., Weinberger, J., \& McClelland, D. C. (1991). Task-intrinsic and social-extrinsic sources of arousal for motives assessed in fantasy and selfreport. Journal of Personality, 59(1), 57-82. https://doi.org/10.1111/j.14676494.1991.tb00768.x

Kruglanski, A. W. (1996). Goals as knowledge structures. In P. M. Gollwitzer \& J. A. Bargh (Eds.), The psychology of action: Linking cognition and motivation to behavior (pp. 599-618). New York, NY: Guilford Press.

Kruglanski, A. W., \& Kopetz, C. (2009). The role of goal-systems in self-regulation. In J. Bargh, P. Gollwitzer \& E. Morsella (Eds.), The psychology of action: Vol 2: The mechanisms of human action (pp. 350-361). New York, NY: Oxford University Press.

LeDoux, J. E. (1996). The emotional brain: The mysterious underpinnings of emotional life. New York, NY: Simon and Schuster.

Lee, Y., Lee, H., \& Tsai, S. (2007). Effects of post-cue interval on intentional forgetting. British Journal of Psychology, 98(2), 257-272. https://doi.org/10.1348/ $000712606 \times 120410$

Levy, B. J., \& Anderson, M. C. (2008). Individual differences in the suppression of unwanted memories: The executive deficit hypothesis. Acta Psychologica, 127(3), 623-635. https:/ / doi.org/10.1016/j.actpsy.2007.12.004

Lindsay, D. S., \& Read, J. D. (2001). The recovered memories controversy: Where do we go from here? In G. M. Davies \& T. Dalgleish (Eds.), Recovered memories: Seeking the middle ground (pp. 71-93). Chichester, UK: Wiley.

Loftus, E. F., \& Pickrell, J. E. (1995). The formation of false memories. Psychiatric Annals, 25(12), 720-725. https:/ /doi.org/10.3928/0048-5713-19951201-07

Loftus, E. F., Polonsky, S., \& Fullilove, M. T. (1994). Memories of childhood sexual abuse: Remembering and repressing. Psychology of Women Quarterly, 18(1), 67-84. https:/ / doi.org/10.1111/j.1471-6402.1994.tb00297.x

Lyle, K. B., \& Johnson, M. K. (2006). Importing perceived features into false memories. Memory, 14(2), 197-213. https:/ / doi.org/10.1080/09658210544000060

Lyle, K. B., \& Johnson, M. K. (2007). Source misattributions may increase the accuracy of source judgments. Memory $\mathcal{E}$ Cognition, 35(5), 1024-1033. https:/ / doi. org $/ 10.3758 /$ bf03193475

MacIntosh, H. B., Fletcher, K., \& Collin-Vézina, D. (2016). "As time went on, I just forgot about it": Thematic analysis of spontaneous disclosures of recovered memories of childhood sexual abuse. Journal of Child Sexual Abuse, 25(1), 56-72. https: / / doi.org/10.1080/10538712.2015.1042564

Malmo, C., \& Laidlaw, T. S. (2010) Symptoms of trauma and traumatic memory retrieval in adult survivors of childhood sexual abuse. Journal of Trauma $\mathcal{E}$ Dissociation, 11(1), 22-43. https:/ / doi.org/10.1080/15299730903318467

Mandler, G. (1980). Recognizing: The judgment of previous occurrence. Psychological Review, 87(3), 252-271. https:/ / doi.org/10.1037/0033-295x.87.3.252

Markus, H., \& Sentis, K. (1982). The self in social information processing. In J. Suls (Ed.), Psychological perspectives on the self (pp. 41-70). Hillsdale, NJ: Erlbaum. 
Mather, M. (2007). Emotional arousal and memory binding: An object-based framework. Perspectives on Psychological Science, 2(1), 33-52. https://doi.org/10. 1111/j.1745-6916.2007.00028.x

Mayes, A. R., Meudell, P. R., \& Pickering, A. (1985). Is organic amnesia caused by a selective deficit in remembering contextual information? Cortex, 21(2), 167-202. https:/ / doi.org/10.1016/s0010-9452(85)80026-5

McNally, R. J. (2007). Betrayal trauma theory: A critical appraisal. Memory, 15(3), 280-294. https: / / doi.org/10.1080/09658210701256506

McNally, R. J. (2012). Searching for repressed memory. In R. F. Belli (Ed.), True and false recovered memories: Toward a reconciliation of the debate (pp. 121-147). New York, NY: Springer.

McNally, R. J., \& Geraerts, E. (2009). A new solution to the recovered memory debate. Perspectives on Psychological Science, 4(2), 126-134. https://doi.org/10. 1111/j.1745-6924.2009.01112.x

Mecklinger, A., Parra, M., \& Waldhauser, G. T. (2009). ERP correlates of intentional forgetting. Brain Research, 1255, 132-147. https://doi.org/10.1016/ j.brainres.2008.11.073

Melchert, T. P. (1999). Relations among childhood memory, a history of abuse, dissociation, and repression. Journal of Interpersonal Violence, 14(11), 1172-1192. https: / / doi.org/10.1177/088626099014011004

Mickes, L., Seale-Carlisle, T. M., \& Wixted, J. T. (2013). Rethinking familiarity: Remember/know judgments in free recall. Journal of Memory and Language, 68(4), 333-349. https:/ / doi.org/10.1016/j.jml.2013.01.001

Middleton, W. (2017). Extreme adaptations in extreme and chronic circumstances: The application of "weaponized sex" to those exposed to ongoing incestuous abuse. Journal of Trauma $\mathcal{E}$ Dissociation, 18(3), 284-303. https://doi.org/10. $1080 / 15299732.2017 .1295378$

Mitchell, K. J., \& Johnson, M. K. (2000). Source monitoring: Attributing mental experiences. In E. Tulving \& F. I. M. Craik (Eds.), The Oxford handbook of memory (pp. 179-195). New York, NY: Oxford University Press.

Moskowitz, G. B., \& Grant, H. (Eds.). (2009). The psychology of goals. New York, NY: Guilford Press.

Moskowitz, G. B., Li, P., \& Kirk, E. R. (2004). The implicit volition model: On the preconscious regulation of temporarily adopted goals. In M. P. Zanna (Ed.), Advances in experimental social psychology, Vol. 36 (pp. 317-413). San Diego, CA: Elsevier Academic Press.

Murayama, K., \& Elliot, A. J. (2011). Achievement motivation and memory: Achievement goals differentially influence immediate and delayed rememberknow recognition memory. Personality and Social Psychology Bulletin, 37(10), 1339-1348. https://doi.org/10.1177/0146167211410575

Nelson, K., \& Gruendel, J. M. (1981). Generalized event representations: Basic building blocks of cognitive development. In M. E. Lamb \& A. L. Brown (Eds.), Advances in developmental psychology, Vol 1 (pp. 131-158). Hillsdale, NJ: Erlbaum.

Nijenhuis, E. R. S. (2015). The trinity of trauma: Ignorance, fragility, and control. Göttingen, Germany: Vandenhoeck \& Ruprecht. 
Patihis, L., Frenda, S. J., \& Loftus, E. F. (2018). False memory tasks do not reliably predict other false memories. Psychology of Consciousness: Theory, Research, and Practice, 5(2), 140-160. https://doi.org/10.1037/cns0000147

Pezdek, K., \& Blandon-Gitlin, I. (2009). Planting false memories for childhood sexual abuse only happens to emotionally disturbed people... not me or my friends. Applied Cognitive Psychology, 23(2), 162-169. https://doi.org/10.1002/ acp.1466

Pezdek, K., Blandon-Gitlin, I., Lam, S., Hart, R. E., \& Schooler, J. W. (2006). Is knowing believing? The role of event plausibility and background knowledge in planting false beliefs about the personal past. Memory $\mathcal{E}$ Cognition, 34(8), 1628-1635. https://doi.org/10.3758/bf03195925

Pezdek, K., Finger, K., \& Hodge, D. (1997). Planting false childhood memories: The role of event plausibility. Psychological Science, 8(6), 437-441. https:/ /doi.org/ 10.1111/j.1467-9280.1997.tb00457.x

Platt, R. D., Lacey, S. C., Iobst, A. D., \& Finkelman, D. (1998). Absorption, dissociation, and fantasy-proneness as predictors of memory distortion in autobiographical and laboratory-generated memories. Applied Cognitive Psychology, 12(7), S77-S89. https:/ / doi.org/10.1002/(sici)1099-0720(199812)12:7\%3Cs77:: aid-acp601\%3E3.0.co;2-c

Putnam, F. W. (1997). Dissociation in children and adolescents: A developmental perspective. New York, NY: Guilford Press.

Putnam, F. W. (2016). The way we are: How states of mind influence our identities, personality and potential for change. New York: International Psychoanalytic Books.

Qin, J., Ogle, C. M., \& Goodman, G. S. (2008). Adults' memories of childhood: True and false reports. Journal of Experimental Psychology: Applied, 14(4), 373-391. https://doi.org/10.1037/a0014309

Quinn, P. C. (2011). Born to categorize. In U. Goswami (Ed.), The Wiley-Blackwell handbook of childhood cognitive development (pp. 129-152). Chichester, UK: WileyBlackwell.

Raymaekers, L., Maarten, J. V. P., Smeets, T., Abidi, L., \& Merckelbach, H. (2011). Underestimation of prior remembering and susceptibility to false memories: Two sides of the same coin? Consciousness and Cognition, 20(4), 1144-1153. https: / / doi.org/10.1016/j.concog.2010.12.010

Read, J. D. (1997). Memory issues in the diagnosis of unreported trauma. In J. D. \& D. S. Lindsay (Eds.), Recollections of trauma: Scientific evidence and clinical practice (pp. 79-108). New York, NY: Plenum.

Read, J. D., \& Lindsay, D. S. (2000). "Amnesia” for summer camps and high school graduation: Memory work increases reports of prior periods of remembering less. Journal of Traumatic Stress, 13(1), 129-147. https://doi.org/10.1023/ a:1007781100204

Roe, C. M., \& Schwartz, M. F. (1996). Characteristics of previously forgotten memories of sexual abuse: A descriptive study. The Journal of Psychiatry $\mathcal{E}$ Law, 24(2), 189-206. https:/ / doi.org/10.1177/009318539602400204

Roediger, H. L., \& McDermott, K. B. (1995). Creating false memories: remembering words not presented in lists. Journal of Experimental Psychology: Learning, Memory, and Cognition, 21(4), 803-814. https://doi.org/10.1037//02787393.21.4.803 
Sahakyan, L., \& Kelley, C. M. (2002). A contextual change account of the directed forgetting effect. Journal of Experimental Psychology: Learning, Memory, and Cognition, 28(6), 1064-1072. https:/ /doi.org/10.1037//0278-7393.28.6.1064

Sahakyan, L., Waldum, E. R., Benjamin, A. S., \& Bickett, S. P. (2009). Where is the forgetting with list-method directed forgetting in recognition? Memory $\mathcal{E}$ Cognition, 37(4), 464-476. https://doi.org/10.3758/mc.37.4.464

Schacter, D. L., \& Buckner, R. L. (1998). Priming and the brain. Neuron, 20(2), 185-195. https://doi.org/10.1016/s0896-6273(00)80448-1

Schank, R. C., \& Abelson, R. P. (1977). Scripts, plans, goals and understanding: An inquiry into human knowledge structures. Hillsdale, NJ: Erlbaum.

Schneider, W. (2011). Memory development in childhood. In U. Goswami (Ed.), The Wiley-Blackwell handbook of childhood cognitive development (pp. 347-376). Chichester, UK: Wiley-Blackwell.

Schneider, W., \& Bjorklund, D. (2003). Memory and knowledge development. In J. Valsiner \& K. J. Connolly (Eds.), Handbook of developmental psychology (pp. 370-403). London, UK: Sage.

Schneider, W., \& Shiffrin, R. M. (1977). Controlled and automatic human information processing: I. Detection, search, and attention. Psychological Review, 84(1), 1-66. https://doi.org/10.1037//0033-295x.84.1.1

Schooler, J. W. (2001). Discovering memories of abuse in the light of metaawareness. Journal of Aggression, Maltreatment E Trauma, 4(2), 105-136. https:/ / doi.org/10.1300/j146v04n02_06

Schore, A. N. (2009). Attachment trauma and the developing right brain: Origins of pathological dissociation. In P. F. Dell \& J. A. O'Neil (Eds.), Dissociation and the dissociative disorders: DSM-V and beyond (pp. 107-141). New York, NY: Routledge.

Schultheiss, O. C., \& Hale, J. A. (2006). Implicit motives modulate attentional orienting to facial expressions of emotion. Motivation and Emotion, 31(1), 13-24. https:/ / doi.org/10.1007/s11031-006-9042-9

Schultz, T., Lawrence Passmore, J., \& Yoder, C. Y. (2002). Emotional closeness with perpetrators and amnesia for child sexual abuse. Journal of Child Sexual Abuse, 12(1), 67-88. https: / / doi.org/10.1300/j070v12n01_04

Shiffrin, R. M., \& Schneider, W. (1977). Controlled and automatic human information processing: II. Perceptual learning, automatic attending, and a general theory. Psychological Review, 84(2), 127-190. https://doi.org/10.1037//0033295x.84.2.127

Shobe, K. K., \& Schooler, J. W. (2001). Discovering fact and fiction: Case-based analyses of authentic and fabricated discovered memories of abuse. In G. M. Davies \& T. Dalgleish (Eds.), Recovered memories: Seeking the middle ground (pp. 95-151). Chichester, UK: Wiley.

Siegel, D. J. (1999). The developing mind: Toward a neurobiology of interpersonal experience. New York, NY: Guilford Press.

Siegel, D. J. (2001). Toward an interpersonal neurobiology of the developing mind: Attachment relationships, "mindsight," and neural integration. Infant Mental Health Journal, 22(1-2), 67-94. https://doi.org/10.1002/10970355(200101/04)22:1\%3C67::aid-imhj3\%3E3.0.co;2-g

Silberg, J. L. (2013). The child survivor: Healing developmental trauma and dissociation. New York, NY: Routledge. 
Sivers, H., Schooler, J. W., \& Freyd, J. J. (2002). Recovered memories. In V. S. Ramachandran (Ed.), Encyclopedia of the human brain (pp. 169-184). San Diego, CA: Academic Press.

Smeets, T., Merckelbach, H., Horselenberg, R., \& Jelicic, M. (2005). Trying to recollect past events: Confidence, beliefs, and memories. Clinical Psychology Review, 25(7), 917-934. https:/ / doi.org/10.1016/j.cpr.2005.03.005

Solinski, S. (2017). Knowing and not knowing: A frequent human arrangement. Journal of Trauma $\mathcal{E}$ Dissociation, 18(3), 397-408. https://doi.org/10.1080/ 15299732.2017.1295423

Talarico, J. M., \& Rubin, D. C. (2003). Confidence, not consistency, characterizes flashbulb memories. Psychological Science, 14(5), 455-461. https://doi.org/10. $1111 / 1467-9280.02453$

Tulving, E. (1985). Memory and consciousness. Canadian Psychology, 26(1), 1-12. https:/ / doi.org/10.1037/h0080017

Tulving, E. (2002). Episodic memory: From mind to brain. Annual Review of Psychology, 53(1), 1-25. https://doi.org/10.1146/annurev.psych.53.100901.135114

Ullman, S. E. (2007). Relationship to perpetrator, disclosure, social reactions, and PTSD symptoms in child sexual abuse survivors. Journal of Child Sexual Abuse, 16(1), 19-36. https://doi.org/10.1300/j070v16n01_02

Van der Hart, O., Bolt, H., \& Van der Kolk, B. A. (2005). Memory fragmentation in dissociative identity disorder. Journal of Trauma $\mathcal{E}$ Dissociation, 6(1), 55-70. https://doi.org/10.1300/j229v06n01_04

Van der Hart, O., Nijenhuis, E. R. S., \& Steele, K. (2006). The haunted self: Structural dissociation and the treatment of chronic traumatization. New York, NY: W. W. Norton \& Company.

Van der Kolk, B. (2014). The body keeps the score: Mind, brain and body in the healing of trauma. New York, NY: Viking.

Van der Kolk, B. A., \& Fisler R (1995). Dissociation and the fragmentary nature of traumatic memories: Overview and exploratory study. Journal of Traumatic Stress, 8(4), 505-525. https: / / doi.org/10.1002/jts.2490080402

Van der Kolk, B. A., Hopper, J. W., \& Osterman, J. E. (2001). Exploring the nature of traumatic memory: Combining clinical knowledge with laboratory methods. Journal of Aggression, Maltreatment $\mathcal{E}$ Trauma, 4(2), 9-31. https: / / doi.org/10.1300/j146v04n02_02

Van IJzendoorn, M. H. (1995). Adult attachment representations, parental responsiveness, and infant attachment: A meta-analysis on the predictive validity of the adult attachment interview. Psychological Bulletin, 117(3), 387-403. https: / / doi.org/10.1037/ /0033-2909.117.3.387

Vandekerckhove, M., \& Panksepp, J. (2009). The flow of anoetic to noetic and autonoetic consciousness: A vision of unknowing (anoetic) and knowing (noetic) consciousness in the remembrance of things past and imagined futures. Consciousness and Cognition, 18(4), 1018-1028. https://doi.org/10. 1016/j.concog.2009.08.002

Vandekerckhove, M., \& Panksepp, J. (2011). A neurocognitive theory of higher mental emergence: From anoetic affective experiences to noetic knowledge and autonoetic awareness. Neuroscience E Behavioral Reviews, 35(9), 2017-2025. https:/ / doi.org/10.1016/j.neubiorev.2011.04.001 
Waring, J. D., Payne, J. D., Schacter, D. L., \& Kensinger, E. A. (2010). Impact of individual differences upon emotion-induced memory trade-offs. Cognition $\mathcal{E}$ Emotion, 24(1), 150-167. https:/ / doi.org/10.1080/02699930802618918

Wenzlaff, R. M., \& Wegner, D. M. (2000). Thought suppression. Annual Review of Psychology, 51(1), 59-91. https://doi.org/10.1146/annurev.psych.51.1.59

Widom, C. S., \& Morris, S. (1997). Accuracy of adult recollections of childhood victimization, part 2: Childhood sexual abuse. Psychological Assessment, 9(1), 34-46. https:/ / doi.org/10.1037//1040-3590.9.1.34

Williams, L. M. (1995). Recovered memories of abuse in women with documented child sexual victimization histories. Journal of Traumatic Stress, 8(4), 649-673. https://doi.org/10.1002/jts.2490080408

Winograd, E., Peluso, J. P., \& Glover, T. A. (1998). Individual differences in susceptibility to memory illusions. Applied Cognitive Psychology, 12(7), S5-S27. https:/ / doi.org/10.1002/(sici)1099-0720(199812)12:7\%3Cs5::aid-acp553\%3E3.0.co;2-d

Winter, D. G., John, O. P., Stewart, A. J., Klohnen, E. C., \& Duncan, L. E. (1998). Traits and motives: Toward an integration of two traditions in personality research. Psychological Review, 105(2), 230-250. https:/ / doi.org/10.1037/0033295x.105.2.230

Woike, B. A. (1994). Vivid recollection as a technique to arouse implicit motiverelated affect. Motivation and Emotion, 18(4), 335-349. https://doi.org/10. $1007 /$ bf02856473

Woike, B. A. (2008). A functional framework for the influence of implicit and explicit motives on autobiographical memory. Personality and Social Psychology Review, 12(2), 99-117. https:/ / doi.org/10.1177/1088868308315701

Yerkes, R. M., \& Dodson, J. D. (1908). The relation of strength of stimulus to rapidity of habit formation. Journal of Comparative Neurology and Psychology, 18(5), 459-482. https://doi.org/10.1002/cne.920180503 